\title{
Andreas Vesalius and Thomas Willis: Their Anatomic Brain Illustrations and Illustrators
}

J.H. Scatliff and S. Johnston

\section{ABSTRACT}

SUMMARY: The brain illustrations of Vesalius and Willis were the first in anatomic history with pictorial accuracy. Their illustrations, illustrators, and methods are discussed. Woodcut blocks were used for the prints of figures in the Vesalian anatomy. Figures of the brain appear to be done after external fixation in the work of Willis.

W ith MR images of the brain now so clear, it is interesting to remember how the first true brain illustrations were done. Although the 3D reality of organ systems began with Da Vinci, it was Vesalius in Padua in the 1500s and his illustrations that led the way with brain drawings approaching those of the present. A hundred years after Vesalius, Thomas Willis and Christopher Wren in Oxford took the accurate depiction of the brain and its vessels further.

There are 25 woodcut figures of brains, reflected dura, skulls, and vessels in Andreas Vesalius' landmark anatomic text The Fabric of the Human Body (Latin: De Humani Corpus Fabrica) Book VII (Figs $1 A,-B) .{ }^{1}$ The

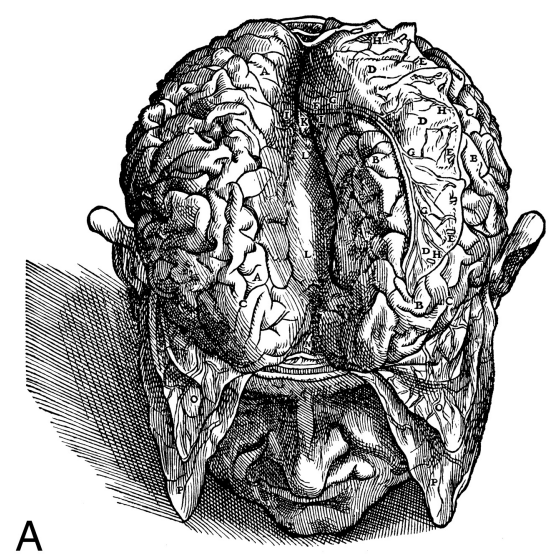

FIG 1. A, De Humani Corpus Fabrica, Book VII, Plate 3 L, Corpus Callosum; D, Falx Separated and Laid on Left Brain. B, Plate 4 E Gyri, GH White Matter O, Choroid Plexus. Modified courtesy of D. Garrison, Department of Classics, Northwestern University. identity of the artist was who did the illustrations is uncertain. It may have been Von Calcar, a Fleming as was Vesalius. ${ }^{2}$ It is known that Von Calcar was a pupil of Titian who lived and worked in Venice. With Vesalius in need of anatomic illustration 25 miles away in Padua, it is not hard to believe that Vesalius asked Titian to recommend an artist or artists.

Vesalius was known to conduct public dissections with as many as 500 observers, including officials of Padua or Bologna and faculty and students of their medical schools. The well-known title page il-

From the Department of Radiology (J.H.S.), School of Medicine, University of North Carolina, Chapel Hill, North Carolina; and Department of Art History (S.J.), George Washington University, Washington, DC.

Please address correspondence to James Scatliff, MD, Department of Radiology, School of Medicine, CB7510, University of North Carolina, Chapel Hill, NC 27599-

7510; e-mail: jiscatliff@med.unc.edu

http://dx.doi.org/10.3174/ajnr.A3766 lustration of the Fabrica shows Vesalius (Fig 2) and a young man possibly sketching what Vesalius was dissecting. The man, however, may only be comparing Galenic anatomic observations with the findings of Vesalius. An older figure may be a symbolic rendition of Galen realizing that some of his anatomic observations 1400 years before were wrong. It is doubtful that an artist working with Vesalius was able to come close enough to the cadaver to accurately illustrate it in the sometimes carnival-like settings. From a medical student's description, ${ }^{3}$ Vesalius dissected rapidly and lectured while he dissected.

Later in a secluded area of the school in Padua, Vesalius may have shown the artist what he wanted drawn and labeled. There is no mention of body or organ preservation techniques at the time. Amputated heads were known to decompose more slowly, allowing the artist greater time to work. Possibly the artist had a photographic memory, allowing him to create drawings later, or from 


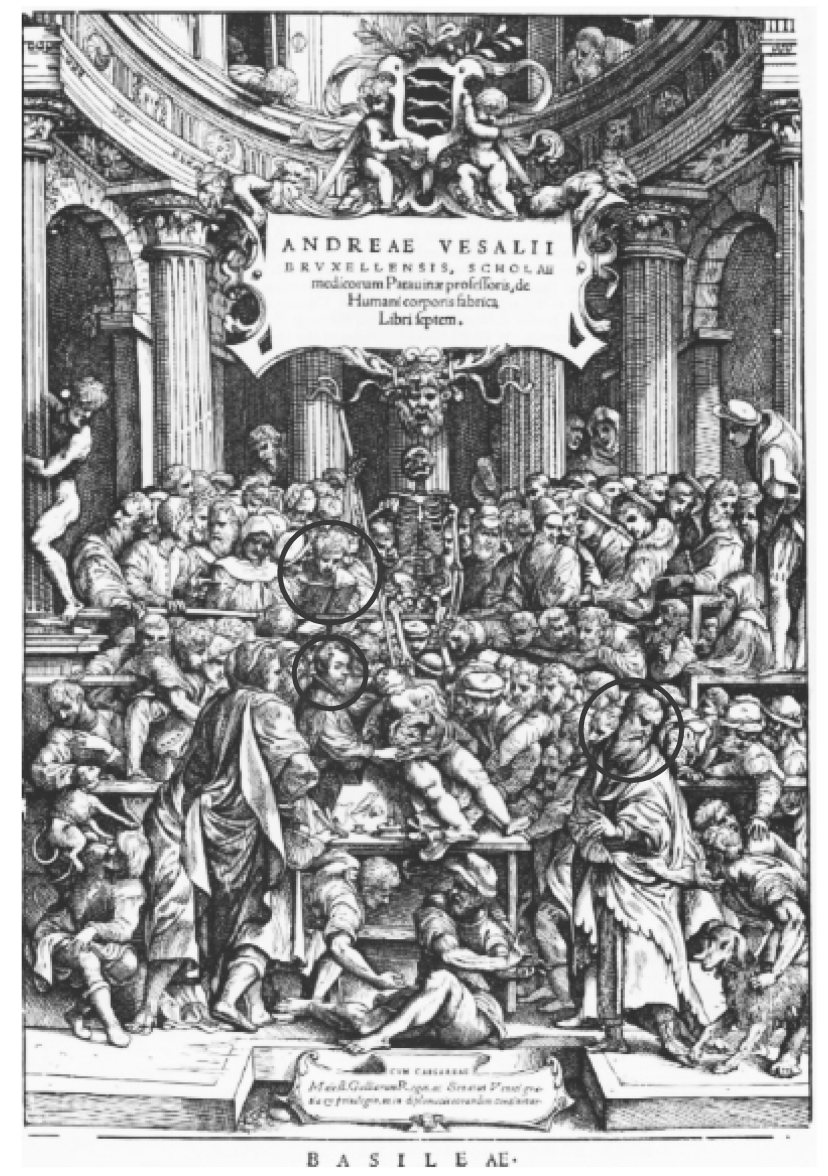

FIG 2. Title page of Fabrica. The lower circle (right) may denote a figure representing Galen. The lower circle left is the anatomist Vesalius. The encircled figure above could be an artist drawing the dissection. Reprinted with permission from Saunders and O'Malley. ${ }^{2}$

sketches made as Vesalius dissected. The multiple figures in the frontispiece of the Fabrica, including one of Vesalius, were most probably completed in a studio rather than live. The nude figure clinging to the pillar on the left is most likely a topographic reminder of the anatomy in it. ${ }^{4}$

The artist, out of necessity, must have drawn rapidly, not only to avoid working with unpleasant odors but also in response to the urgency from Vesalius to complete his work. The time it took the artist to make individual drawings is not known. If Netter, ${ }^{5} 500$ years later, can be used as a guide, multiple initial drawings are needed to portray the body in certain positions or in motion. For the final illustration of a stellate ganglion block, which Netter did for a CIBA Symposium article, ${ }^{5}$ as many as 8 preliminary sketches were used to show the position of the body, the stellate ganglion, and the needle direction for it. To produce the Fabrica with some dispatch, Vesalius may have encouraged the artist to maintain connections with dealers of art supplies and with skilled woodblock cutters in Venice. To prepare the Fabrica and the shorter Epitome drawings by Andreas Vesalius for printing, woodblock engravings were used. Some artists of the 16th century, including Albrecht Durer, cut illustrations directly into the woodblocks. The figures for Vesalius' work however were done by tracing the artist's drawing on the blocks. ${ }^{3}$

Although Venice was a major center for international book

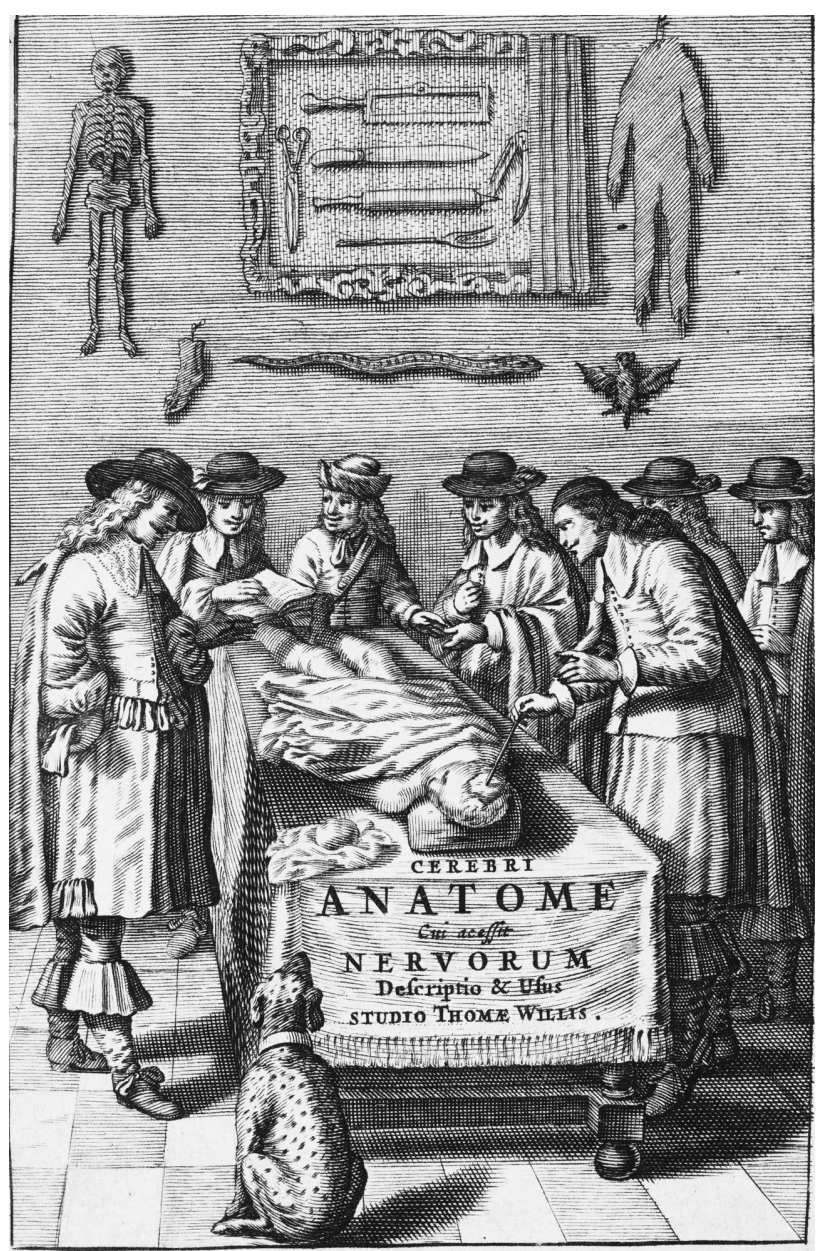

FIG 3. Title page of Cerebri Anatome (2nd ed, 1664). ${ }^{8}$ Illustration shows Willis on the right of the cadaver. The figure in the left foreground may be Christopher Wren. Courtesy of Cushing/Whitney Medical Library, Yale University.

publication at the time, Vesalius decided to have both the Fabrica and the Epitome printed in Basel. What is amazing, 200 of the blocks survived until World War II, when they were destroyed in the Allied bombing of Munich. They had been discovered in the 1930s in an attic storage area of the University of Munich by Wiegland, who described them in the Three Vesalian Essays. ${ }^{3}$ The completed woodcut blocks were most likely shipped from Venice to Milan and then over the Alps to Basel in August 1542. The mode of transport of the blocks, the largest being approximately $10 \times 17$ inches $(25.4 \times 43.18 \mathrm{~cm})$ is not known.

Basel, in Reformation Europe, with its political diversity and location on the other side of Alps, was farther from Rome and the possible prohibitions of the Church. It had also begun to rival Venice in the superiority of its printing. The Basel publisher of the Fabrica and Epitome, the philologist Johannes Oporinus, ${ }^{2} \mathrm{di}-$ rected a respected firm, known for the quality of its work. Oporinus was, in addition to being a publisher, a scholar of both Latin and Greek. Vesalius may have thought that with the philologist's help, his Latin text could be printed accurately. The marginal notes in Greek in the Fabrica may have been written by Oporinus. In addition, the distribution network in 1544 for the sale of his books was probably greater in Germany. It is interesting that Ve- 

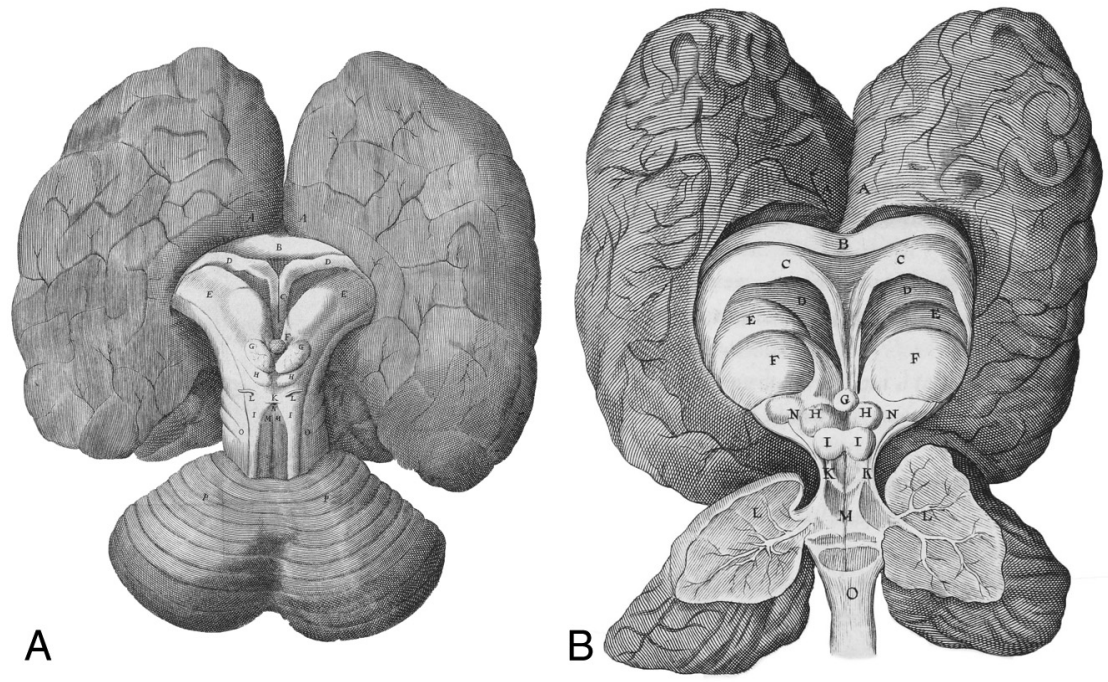

FIG 4. Cerebri Anatome, pages 43 and 51 (2nd ed, 1664). ${ }^{8} A$, Base of the brain. B, Open brain. The darker color of the cerebral hemispheres and cerebellum is probably due to external fixation in wine and vinegar with the brain resting on its base in a receptacle. Courtesy of Rubenstein Rare Book and Manuscript Library, Duke University.

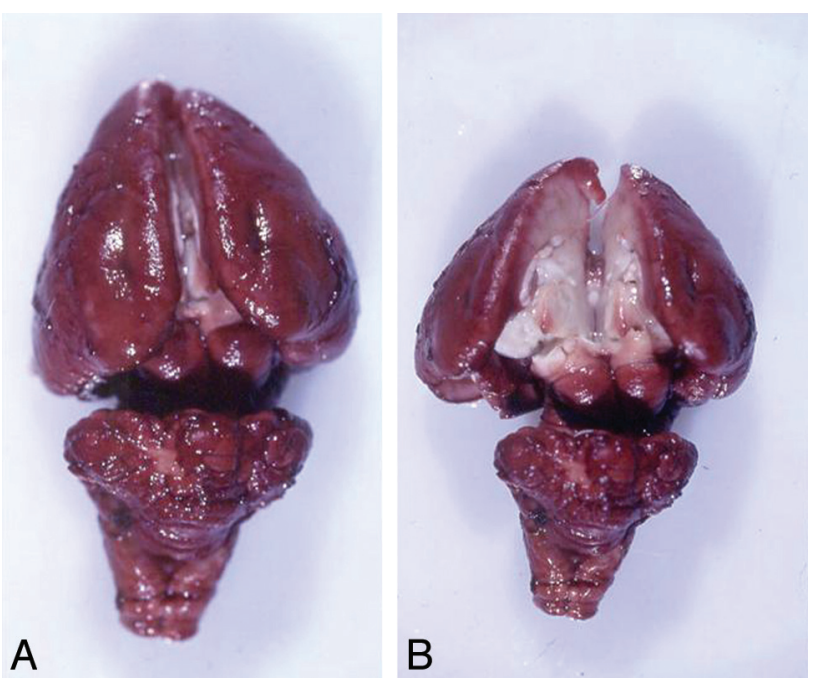

FIG 5. Surface $(A)$ and interior $(B)$ of a rabbit brain after 6 days showing the central area of brain not reached by fixative.
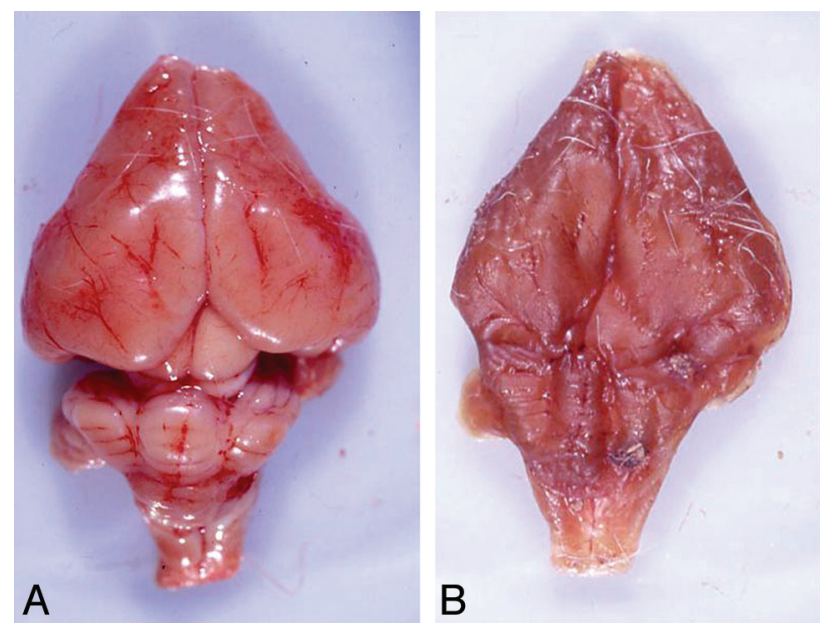

FIG 6. $A$, Rabbit brain without fixation 2 hours after removal from cranium. $B$, Loss of anatomic features of brain after 6 days without fixation. salius, at the age of 28, left the University of Padua shortly after the publication of Fabrica and Epitome to become the personal physician to Emperor Charles V.

The anatomic information described in Fabrica and Epitome spread rapidly throughout Europe. It increased with a second printing of these books by the same firm in the 1550s by using the original woodblocks. The metal etching technique first used for armorial design replaced the woodblock technique beginning in the middle 1500s. The English engraver and publisher, Thomas Geminus, transferred drawings made for the Fabrica woodcuts to copper plates in $1545 .{ }^{6}$ By the middle of the 17 th century, copper etching was used for the illustration of the anatomic observations of Thomas Willis and the Oxford school.

The first recording of Willis' brain dissection and observations came in his work, the Cerebri Anatome. ${ }^{7}$ It is known from a letter that Richard Lower, one of Willis' students, wrote to Robert Boyle that Willis began his human brain dissections in the fall of $1660{ }^{8}$ The dissections were conducted in the rooms of Christ Church, Willis' Oxford school, and in Willis' home and laboratory in Beam Hall, on Merten Street in Oxford. Willis gave Lower, who was 10 years younger, credit in his preface in the Cerebri Anatome for being a "skillful anatomist whose knife and wit I willingly acknowledge." ${ }^{\text {7 }}$ It may be that Lower and Willis, along with Willis' Oxford associates, Thomas Millington and Edmund King, were principally involved in not only procuring bodies but also in the removal and fixation of brains for study, description, and illustration. This group made it possible for Willis to take time from his busy Oxford clinical practice to make the observations and preparation for the Cerebri Anatome. Christopher Wren was asked to do the illustrations.

Wren, a graduate of Oxford's Wadham College, was known not only for his intelligence and inventive mind but as an excellent mathematician, model builder, and draftsman. ${ }^{9}$ Willis stated in the preface of the Cerebri Anatome that "Wren delineates with his most skillful hand many of the figures of the brain and skull whereby work might be more exact."7 The frontispiece of the second edition of the Cerebri Anatome (Fig 3) quite possibly depicts Willis examining, with colleagues, a cadaver brain that has been exposed. In the fashionable dress of the time, the opposing figure may be Wren, the ascendant architect of the restoration of Charles II.

In all probability, Wren did not draw the brain before fixation; the dark cerebral hemispheres suggest fixation performed with the cerebral hemispheres up and covered with fixative. The brain could then be sketched later, anatomically intact, by Wren. The use of "spirits of wine" for organ preservation ${ }^{8}$ was described by Robert Boyle in the mid-1600s. Most likely the wine used was port, due to its higher alcohol content, mixed with vinegar. William Petty, an early Oxford colleague of Willis, purportedly kept a 

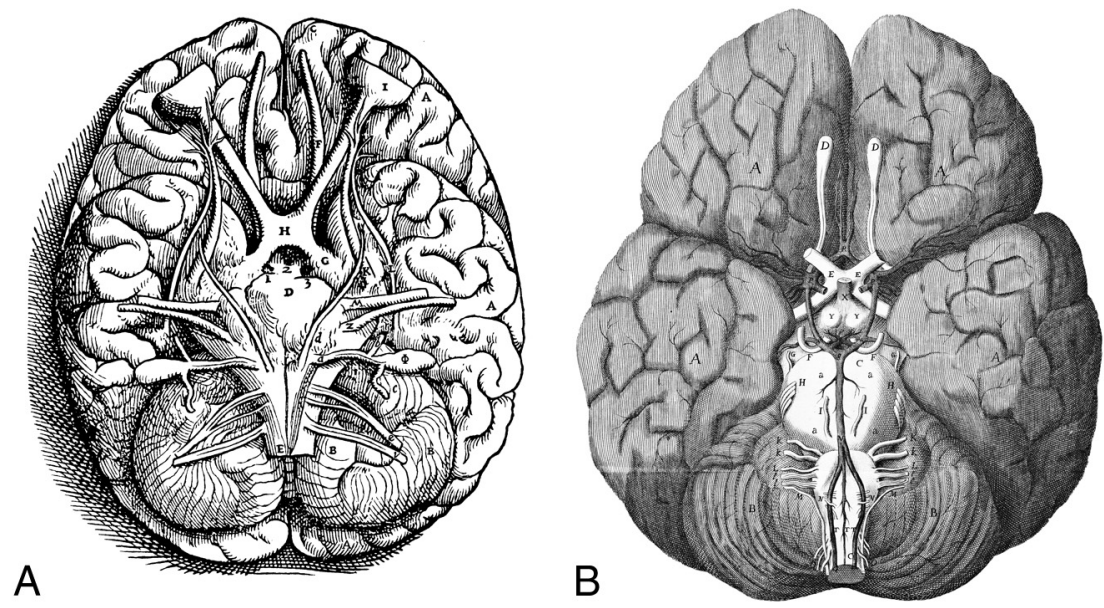

FIG 7. A, Fabrica, Book VII, Plate 24. The brain stem and nerves are inaccurately drawn due either to lack of fixation or unsatisfactory removal from the cranium. B, Cerebri Anatome, page 25. The brain stem with nerves and vessels, including the circle of Willis, is shown by Wren almost as in an architectural drawing. Fabrica courtesy of D. Garrison, Department of Classics, Northwestern University. Cerebri Anatome courtesy of Rubenstein Rare Book and Manuscript Library, Duke University.

corpse "soused and pickled." ${ }^{8}$ With the brain resting on the bottom of the container, the fixative was unable to reach its interior; the Wren figures (Fig 4) from the Cerebri Anatome seem to bear this out. This observation is replicated with rabbit brains, as shown in Fig 5.

To study brain circulation, Willis, Lower, and Wren infused various liquids in the internal carotid arteries before fixation. Lower wrote to Boyle that all parts of the brain "were imbued with the same color after the carotids were injected." ${ }^{8}$ There was no indication from Lower, however, that fixation of the brain was performed by carotid artery injection. The fact that the Wren drawing showed the brain stem in white is a further point in favor of external fixation of the brain without the brain stem being reached by the fixative. An alternative consideration is that Wren decided to contrast the cerebrum in a darker color than the brain stem, though differences in fixation seem more likely. The desiccation of the unfixed rabbit brain at 6 days (Fig 6) emphasizes the difference in the unfixed Vesalian brain drawn 100 years previously. Blood vessels and cranial nerves are not shown, and the brain stem is not well-defined. On the other hand, the Wren illustrations, though showing considerable detail, have an almost architectural appearance. A brain drawn for Vesalius is contrasted with that of Wren in Fig 7.

The preparation for printing, the printing, and the sale of the first and second editions of Cerebrum Anatome are of interest. It would appear that a skilled German-Dutch engraver living in the Oxford area etched Wren's drawings onto copper plates, along with Willis Latin text, for printing in the shop of James (Fletcher) Flesher. ${ }^{7}$ The site of Flesher's printery is unknown but was probably close to St. Paul's Cathedral, London. The title page of the Quarto Edition cites Flesher as the printer and Roycroft as the printer of the smaller Octavo Edition in 1664. The title page also indicates that the financing was by James Martyn and James Allestry and that the books were sold by them in their shop at The Sign of the Bell, adjacent to the churchyard of St. Paul's, in $1664 .^{7}$ Martyn and Allestry were booksellers for the Royal Society, which may have prompted Willis and Wren, Society members, to use their services. The Great Fire of London of 1666 destroyed both the printing houses and the booksellers' shops around St. Paul's. Fortunately, the first 2 editions of the Cerebri Anatome were printed and sold before the fire. In all probability, the fire caused the next editions to be published in Amsterdam. The same copper plates used in London were used in the 1668 Amsterdam editions. Further publication of the Cerebri Anatome in Latin occurred in Lyon, Geneva, Amsterdam, and Venice between 1676 and 1681.

Although interest in illustrations of human anatomy including the brain went forward in the 18th century, publication with the impact of the Fabrica and Cerebri Anatome was not equaled until the 19th century.

The next major anatomic text of this time was Gray's Anatomy, published in the mid-19th century. Two physicians working together, Henry Gray and Henry Carter, Gray's illustrator, brought superb anatomic and functional information forward. Carter's illustrations still appear in the current 40th edition of the book, ${ }^{10}$ along with the helpful color diagrams, radiographs, and images, as well as tissue and cellular anatomy revealed so clearly with scanning electron micrographs.

The 20th century anatomists and their illustrators, Pernkopf, Sobbata, Hollingshead, and Netter, to name but a few, have advanced the knowledge of the human brain and body immensely, beginning with the seminal works of Vesalius, Willis, and their illustrators.

\section{Acknowledgments}

The authors thank Jeremy Boomhower for his help in preparing the manuscript and Dwight Bellinger, DVM, for the preparation of the animal brains.

\section{REFERENCES}

1. Singer C. Vesalius on the Human Brain. London: Oxford University Press; 1952

2. Saunders JB, O'Malley CD. The Illustrations from the Works of Andreas Vesalius of Brussels, 1514-1564. Berkeley: University of California Press; 1950

3. Weigland W. Three Vesalian Essays. New York: Macmillan; 1952

4. Lind LR. The Epitome of Andreas Vesalius. New York; 1946

5. Netter FJ. A Medical Illustration at Work. CIBA Symp 1949;10:1087-92

6. Furdell EL. Publishing and Medicine in Early Modern England. Rochester, New York: University of Rochester Press; 2002

7. Willis T. Cerebri Anatome. 2nd ed. London, UK; Flesher J, 1664

8. Hughes JT. Thomas Willis: 1621-1675: His Life and Work (Eponymists in Medicine Series). Dorchester, UK: Dorset Press; 1991

9. Jardine L. On a Grander Scale: The Outstanding Career of Sir Christopher Wren. London: HarperCollins; 2002

10. Standring S. Gray's Anatomy. $40^{\text {th }}$ ed. London, UK: Churchill Livingston Elsevier; 2008 